\title{
Gangrene developing after minor surgery in a patient with undiagnosed systemic lupus erythematosus and lupus anticoagulant
}

\author{
B. K. JINDAL, M. F. R. MARTIN, AND A. GAYNER \\ From Leeds General Infirmary, Leeds LS1 3EX
}

SUMMARY We report a case of progressive peripheral ischaemia and gangrene as a presenting feature of systemic lupus erythematosus. It developed in a previously asymptomatic 40-year-old woman following minor surgery to her toe. Eventually she required a below-knee amputation and despite systemic corticosteroids continued to deteriorate, presenting later with signs of systemic intravascular thromboses. Histopathology and immunofluorescence on vessels repeatedly failed to demonstrate any evidence for vasculitis. A full coagulation screen confirmed the presence of 'lupus' anticoagulant. A plasma exchange was performed to remove circulating immunoglobins and she made a rapid and sustained recovery. Peripheral gangrene has not previously been described in association with lupus anticoagulant. We would suggest that in all cases of systemic thrombosis or unexplained peripheral vascular ischaemia lupus anticoagulant should be considered.

\section{Case report}

A 40-year-old housewife was admitted for a Zadek's procedure to an onychogryphotic right hallux. She had no previous history of chronic disease, she smoked approximately 30 cigarettes daily, and a complete physical examination gave normal results.

Examination 9 days postoperatively revealed a clean healthy wound, but after 3 weeks a dusky cellulitis of the forefoot developed which failed to respond to ampicillin and flucloxacillin. She was admitted with severe ischaemic pain, a pyrexia $37 \cdot 8^{\circ} \mathrm{C}$, and gangrenous right first, second, and third toes with mottling of the forefoot. On examination her right dorsalis pedis pulse was impalpable, but there were no other abnormalities. A full blood count revealed a leucopenia and ESR $97 \mathrm{~mm} / \mathrm{h}$. Lipid profile, glucose tolerance curve, liver function, urea and electrolytes, cryoglobulins, cold agglutinins, Wassermann reaction and VDRL were all normal. Urine analysis was negative. Antinuclear factor 1 in 100

Accepted for publication 5 May 1982.

Correspondence to Dr M. F. R. Martin, Rheumatism Research Unit, School of Medicine, 36 Clarendon Road, Leeds LS2 9PJ. (homogeneous), DNA binding 52\% (normal less than $25 \%$ ), IgG $210 \mathrm{IU} / \mathrm{ml}$ (normal 128-199 IU/ml), IgA $330 \mathrm{IU} / \mathrm{ml}$ (normal 99-181 IU/ml), IgM 299 $\mathrm{IU} / \mathrm{ml}$ (normal 60-129 IU $/ \mathrm{ml}$ ), complement $93 \mathrm{mg} / \mathrm{dl}$ (normal 104-161 mg/dl), rheumatoid factor titre positive. (SI conversion: $\mathrm{IU} / \mathrm{ml} \times 1000=\mathrm{IU} / \mathrm{l} ; \mathrm{mg} / \mathrm{dl}$ $\times 0 \cdot 01=\mathrm{g} / \mathrm{l}$.) Clotting studies showed a prothrombin time 16 seconds (normal 13 seconds), activated partial thromboplastin time 54 seconds (normal 34 seconds), kaolin clotting time 36 seconds (normal 28 seconds), thrombin clotting time 18 seconds (normal 14 seconds), euglobulin clot lysis time 270 seconds (increased), fibrinogen and fibrin degradation products normal. These changes were consistent with circulating 'lupus' anticoagulant.

Arteriography showed marked narrowing of all her arteries in the right forefoot, probably secondary to severe tissue oedema, with an absent dorsalis pedis and planter arch. A mid tarsal amputation was performed, but at operation there was only a gradual ooze of blood with minimal spurting from the stump vessels.

Histology on the forefoot was consistent with ischaemic necrosis, showing only fibrin plugging of small vessels without involvement of the vessel wall 
or associated vasculitis. Immunofluorescence and immunoperoxidase techniques failed to show any evidence of immune complex deposition within the vessel walls.

On closer questioning the patient gave no history of previous arthritis or vasculitis, although she mentioned symptoms of mild Raynaud's phenomenon and the recent development of photosensitive rashes. Moreover her mother had severe rheumatoid arthritis.

Healing was very limited, and she continued to have severe ischaemic pain. The stump became dusky and mottled with a spreading cellulitis, and it became necessary to perform a below-knee amputation. Treatment was started immediately after operation with prednisolone $60 \mathrm{mg}$ daily, and a marked general improvement occurred. The operation site remained healthy and she was discharged home after 2 weeks, despite circulating lupus anticoagulant still being detectable.

A few weeks later she was readmitted with pleuritic chest pain, abdominal pain, and haematuria. A chest $x$-ray showed 2 areas of recent pulmonary infarction. A systemic thrombotic process was suspected, and a 3-litre plasma exchange was successfully performed to remove circulating abnormal immunoglobulins. Repeat clotting studies showed a return to normal values within 48 hours, and a full reduction of steroids became possible over the following weeks. She has continued well during the last year. Her immunology profile is unchanged, and the circulating lupus anticoagulant remains undetectable.

\section{Discussion}

Gangrene is a rare complication of SLE and is even rarer as a presenting feature. ${ }^{1}$ Dubois ${ }^{2}$ reviewed 520 cases of lupus and only reported a $1.3 \%$ incidence of gangrene of the extremities. A review ${ }^{13-5}$ of this condition over the last 25 years has yielded 8 patients, and in each one a necrotising vasculitis has been regarded as the aetiological factor in the production of peripheral gangrene. Interestingly, 5 of these 8 cases were smokers, which may have been an additional risk factor.

Spontaneously acquired circulating anticoagulants have been reported in a variety of systemic diseases, ${ }^{67}$ directed against specific coagulation factors (XII, XI, IX, and VIII). Approximately $50 \%$ of all these cases have systemic lupus erythematosus, and the most common abnormality of the coagulation system in SLE is the so-called lupus anticoagulant, that acts by interfering with the activation of prothrombin by the prothrombin activator complex.(factor $\mathrm{Xa}, \mathrm{V}$, calcium, and phospholipid). ${ }^{8-10}$ The evidence suggests that the anticoagulant inhibits specifically the phospholipid portion of the complex. In some $5-10 \%$ of all patients with SLE circulating anticoagulant is detectable. ${ }^{11}$

Patients usually have a prolonged, activated, partial thromboplastin time, with a small increase in prothrombin time. The anticoagulant is considered to be either an IgG or IgM immunoglobulin, though occasionally both classes may appear together in the same individual. ${ }^{71}$ There have been few reports of any associated bleeding tendency in patients with anticoagulant except in cases with coexisting thrombocytopenia ${ }^{6}{ }^{6}$ and paradoxically increased thrombotic activity has been observed.

Mueh et al. ${ }^{12}$ reviewed 35 cases with lupus anticoagulant, and in 8 of these there was evidence of clinical thromboses. Three further patients had a history of thrombotic episodes before the discovery of their lupus anticoagulant. Peripheral gangrene has not previously been described in association with these thrombotic episodes.

Recent reports of thromboses in SLE have highlighted the lack of inflammatory vascular disease.$^{13-15}$ Carreras et al. ${ }^{16}$ have demonstrated in one patient a circulating inhibitor that reduces prostacyclin $\left(\mathrm{PGI}_{2}\right)$ formation. In-vitro studies have also shown that plasma from patients with SLE can inhibit $\mathrm{PGI}_{2}$ activity. ${ }^{17}$ These observations may provide an explanation for the observed thrombotic episodes occurring without evidence of vessel disease or vasculitis.

Our patient, with definite SLE (American Rheumatism Association criteria), who developed gangrene after minor surgery, had circulating lupus anticoagulant and despite high prednisolone dosage later developed widespread systemic thromboses. Plasma exchange proved effective and rapidly corrected all clotting abnormalities. The lack of any histopathological or immunopathological evidence of vasculitis, arteritis, or immune complex deposition within the vessel walls suggests that the intraluminal thromboses were related to the coagulation defect. The presence of lupus anticoagulant, though rare, should be considered in all cases of peripheral vascular insufficiency when the aetiology is unknown.

We thank Mr E. B. Longton for allowing us to report a patient under his care.

\section{References}

1 Dubios E L, Arterberry J D. Gangrene as a manifestation of systemic lupus erythematosus. JAMA 1962; 181: 366-74.

2 Dubois E L, Lupus Erythematosus. 2nd ed. Los Angeles: University of Southern California Press, 1974: 296-305.

3 Gladstein G S, Rynes R I, Parhami N, et al. Gangrene of a foot secondary to systemic lupus erythematosus with large vessel vasculitis. J Rheumatol 1979; 6: 549-53. 
4 Keat E C B, Shore J H. Gangrene of the legs in disseminated lupus erythematosus. $\mathrm{Br}$ Med J 1958; i: 25-7.

5 Cheah J S. Systemic lupus erythematosus in a Chinese woman presenting with gangrene of the fingers. Aust NZ J Med 1973; 3: $197-9$.

6 Boxer M, Ellman L, Carvalmo A. The lupus anticoagulant. Arthritis Rheum 1976; 19: 1244-8.

7 Schleider M A, Nachman R L, Jaffa E A, et al. A clinical study of the lupus anticoagulant Blood 1976; 48: 499-509.

8 Margolis A Jr, Jackson D P, Ratnoff O D. Circulating anticoagulants: A study of 40 cases and a review of the literature. Medicine (Baltimore) 1961; 40: 145-202.

9 Bowie E W, Thompson J H, Cascuzzi P A, Owen G A. Thrombosis in SLE despite circulating anticoagulants. J Lab Clin Med 1963; 62: 416-30.

10 Di Sabatrino C A. A circulating anticoagulant directed against factor XIa in systemic lupus erythematosus. Arthritis Rheum 1979; 22: 1135-8.
11 Lechner K. A new type of coagulation inhibitor. Thrombosis et Diathesis Haemorrhagica 1969; 21: 495-7.

12 Mueh J R, Herbst K D, Rapaport S I. Thrombosis in patients with the lupus coagulant. Ann Intern Med 1980; 92: 156-9.

13 Johnson R T, Richardson E P. The neurological manifestations of systemic lupus erythematosus. Medicine (Baltimore) 1968; 47: 337-69.

14 Paterson A, Timperley W, Slater D N. Coagulation abnormalities in fatal cerebral lupus erythematosus. J Soc Med 1981; 74: 51-5.

15 Slater D. 'Lupus' and prostacyclin formation. Lancet 1981; i: 393.

16 Carreras L O, Defreyn G, Machin S J, et al. Arterial thrombosis, intrauterine death and 'lupus' anticoagulants. Detection of immunoglobulin interfering with prostacyclin formation. Lancet 1981 ; i: $244-6$.

17 McVerry B A, Machin S J. Reduced prostacyclin activity in systemic lupus erythematosus. Ann Rheum Dis 1980; 39: 524-5. 